International Journal of Industrial Engineering Research and Development (IJIERD)

Volume 7, Issue 2, May-December 2016, pp.23-30, Article ID: IJIERD_07_02_003

Available online at https://iaeme.com/Home/issue/IJIERD?Volume=7\&Issue $=2$

ISSN Print: 0976 - 6979 and ISSN Online: 0976 - 6987

DOI: https://doi.org/10.34218/IJIERD.7.2.2016.003

(C) IAEME Publication

\title{
DESIGN AND DEVELOPMENT OF TOOL KIT FOR TEAM PERFORMANCE
}

\author{
Vishal V Vernekar \\ Dept. of Industrial Engineering and Management, \\ BMSCE, Bengaluru-19, India \\ Mahendra NG \\ Dept. of Industrial Engineering and Management, BMSCE, \\ Bengaluru-19, India
}

\section{Ramesh KT}

Asst. Professor, Dept of Industrial Engineering and Management,

BMSCE, Bengaluru-19, India

\section{Jyothi AD}

Principal Software Quality Engineer, EMC Corporation, Bengaluru-48, India

\begin{abstract}
Henry Ford once quoted that "coming together is the beginning. Keeping together is progress. Working together is success." Hence performing activities in a group has a different value of its own and yields a better result.

An attempt has been made to develop a tool kit which where a game is played with two teams with various scenarios pertaining to flow of information and are validated by statistical tests regarding data collections and the behaviour of individuals are validated using the fuzzy logic approach. The developed kit will act as a pedagogy tool which help organisation in developing an effective team / group for meeting its long \& short term organisations goal.
\end{abstract}

Further, the toolkit can have its application in human resource management. It consists of selection, training and evaluating of team members.

Key words: Team Performance, Game, Tool Kit, Fuzzy Sets.

Cite this Article: Vishal V Vernekar, Mahendra NG, Ramesh KT and Jyothi $\mathrm{AD}$, Design and Development of Tool Kit for Team Performance, International Journal of Industrial Engineering Research and Development, 7(2), 2016, pp. 23-30

https://iaeme.com/Home/issue/IJIERD?Volume=7\&Issue $=2$ 


\section{INTRODUCTION}

The lauda air flight disaster on May, 1991 resulted in huge loss to Boeing (Aeroplane manufacturer) because they outsourced the parts to other manufacturers as a supply chain strategy, because of time constraints they outsourced the parts to third suppliers, as a result there were errors in the parts. This incurred huge loss to the company. The main reason behind this was lack of proper information flow among the suppliers, which resulted in poor communication and coordination. Hence Team building is important aspect for an organisation, which involves joint action by a group of people, in which individual interests are subordinated to group unity and efficiency. It's a collective term for various types of activities used to enhance social relations and define roles within teams. These often involve collaborative tasks.

The formal definition of team-building includes the following pillars. (B W Tuckman in work 'Developmental sequence in small groups')

This also represents objective of a team:

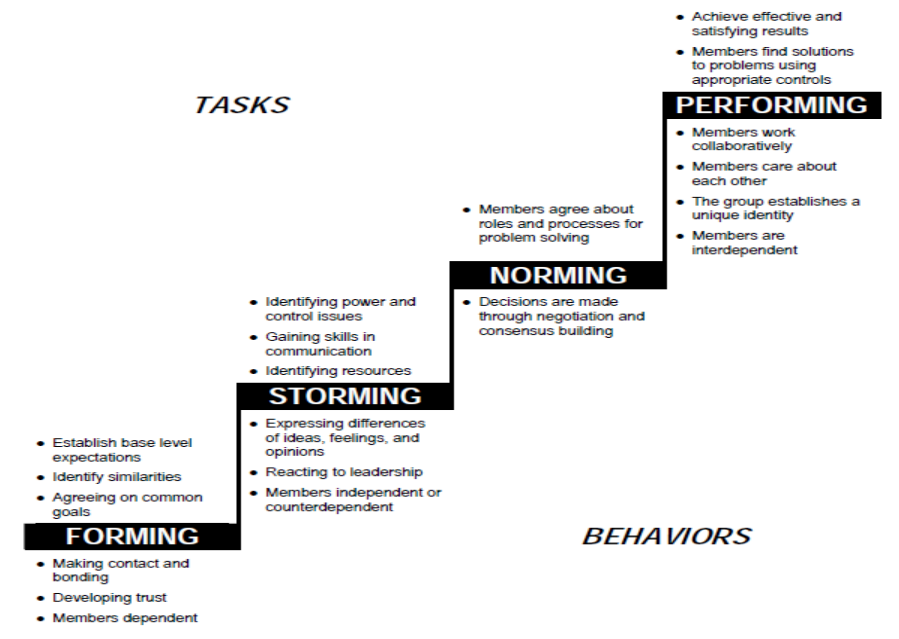

Figure 1 Tuckman's stages of team development (1965, 'Developmental sequence in small groups')

- Goal setting: Goal setting emphasizes setting objectives and developing individual and team goals. Team members become involved in action planning to identify ways to achieve goals.

- Role clarification: Role clarification emphasizes increasing communication among team members regarding their respective roles within the team. Team members improve their understanding of their own and others' respective roles and duties within the team.

- Interpersonal-relationship management: Interpersonal-relations management emphasizes increasing teamwork skills (i.e. mutual support, communication and sharing of feelings). Team members develop trust in one another and confidence in the team

- Problem solving: Problem solving emphasizes identifying major task-related problems within the team. Team members become involved in action planning, implementing solutions to problems identified, and evaluating those solutions. 


\section{PROBLEM DEFINITION}

A simple game can be useful in improving cooperation, to practice communication, to improve social ability of the member and emotional management.

Hence the need for a game, which is considered as the best way to promote team building and develop various qualities like communication, better understanding among the team members was considered.

The scopes of the project aim at developing other essential qualities like

- To motivate team members

- To promote creativity

- To develop problem solving skills

- To identify team's strengths and weaknesses

- To help in defining the objectives and goals clearly

- To assign the roles of team members.

\section{THE DESIGN OF THE TOOLKIT}

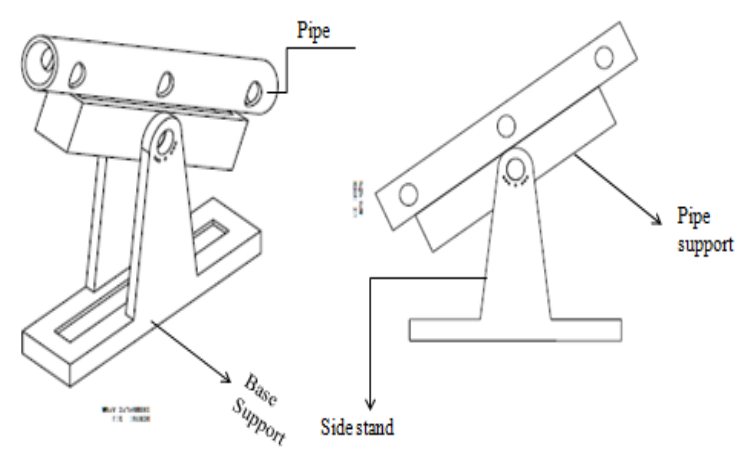

Figure 2 The design of the toolkit

The design comprises of a base support, two side-plates supports to clamp the pipe support. The pipe is rested on the pipe support. The side supports are graduated on either side for setting the angles with a plug in key.

The design is considering three parameters of team performance. (Roger Guimera et.al in work 'team assembly mechanisms determine collaboration network structure and team performance)

- Time

- Resource

- Difficulty 

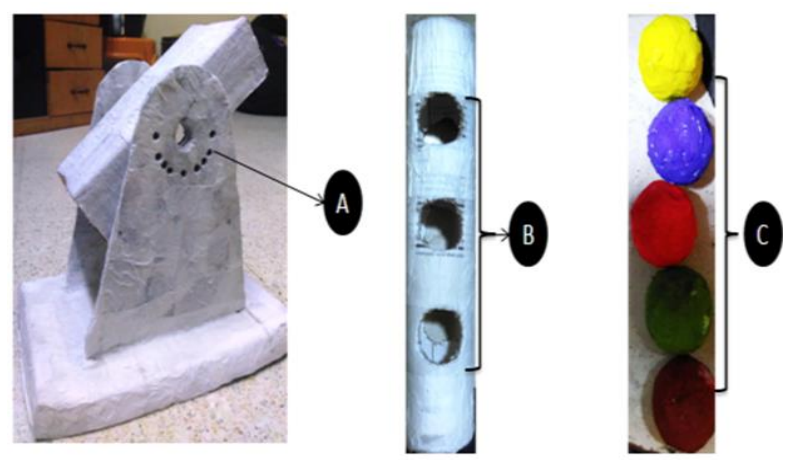

Figure 3 The prototype.

The time factor ('A'-in figure 3 ) is measured by inclination of the pipe support. As the angle of inclination increases there is less time in completing the game.

The no of holes (' $\mathrm{B}$ '-in figure 3) present on the pipe represents availability of human resource to perform the experiment. One can alter the no of players based on difficulty of project.

The combination of colour balls (' $\mathrm{C}$ '-in figure 3) will represents the level of difficulty of the experiment. The level of difficulty is as follows

- Easy

- Medium

- Hard

\section{COMPARISON DESIGNS}

The designs given below are taken into consideration in finalizing our design. The supporting mechanism shown in figure 4 is adopted with hinging mechanism in centre rather than at sides.

Similarly, the pin lock mechanism of catapult design is incorporated in our design other than hinging.

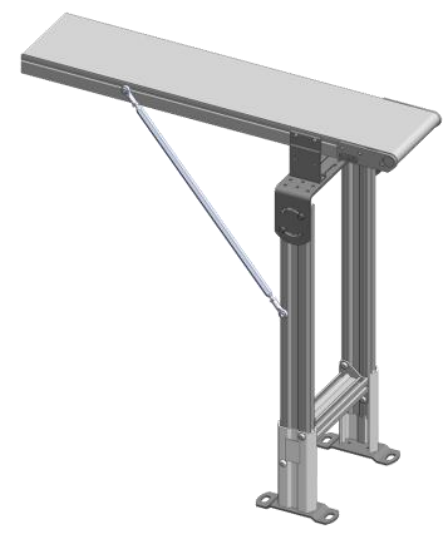

Figure 4 Hinged at one end cantilever mechanism 
Table 1 Comparison of the designs

\begin{tabular}{|l|l|l|l|l|}
\hline & \multicolumn{1}{|c|}{ Material } & Feasibility & \multicolumn{1}{c|}{ Durability } & \multicolumn{1}{c|}{ Area of work } \\
\hline Figure 2 & Wood \& Plastic & Good & High & Team performance \\
\hline Figure 3 & M.S steel & Average & Less & Cantilever support \\
\hline Figure 4 & Wood & Good & Average & Design of experiment \\
\hline
\end{tabular}

The observations made have to be validated with proper tool. Many tools been selected among which fuzzy logic is selected. The reason for selection of fuzzy logic is as follows.

\section{FUZZY LOGIC}

The validation of the toolkit is done by fuzzification and defuzzification (three input one output fuzzy logic)

It is an approach of computing based on "degrees of truth" rather than the usual "true or false" (1 or 0) Boolean logic on which the modern computer is based. (L.A. Zadeh, "Fuzzy Sets,")

- One of the reasons for the popularity of Fuzzy Logic Controllers is its logical resemblance to a human operator.

- It operates on the foundations of a knowledge base which in turn rely upon the various if then rules, similar to a human operator ${ }^{[4]}$. Unlike other control strategies, this is simpler as there is no complex mathematical knowledge required.

- The figure below gives an clear picture about how fuzzy logic is being carried out

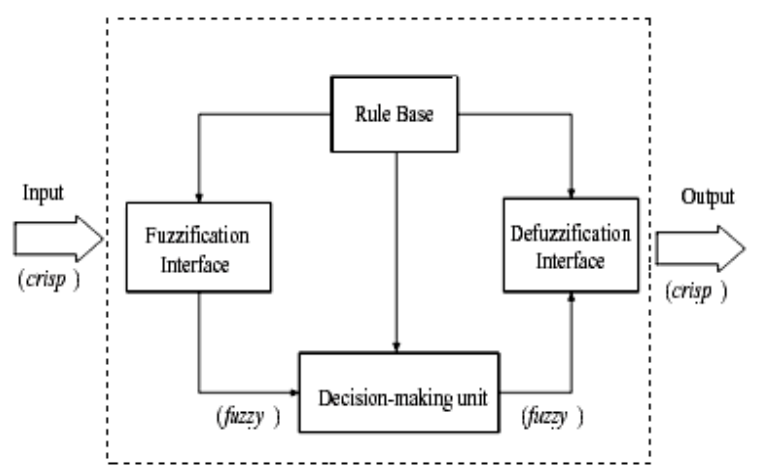

Figure 5 Basic configuration of fuzzy logic system (L.A. Zadeh, "Fuzzy Sets,")

\section{THREE INPUT-ONE OUTPUT FUZZY LOGIC CONTROL}

Among the various shapes of fuzzy number, triangular fuzzy number (TFN) is the most popular one. This is more suitable for non-precise inputs from which a crisp value can be obtained

Definition (Triangular fuzzy number) It is a fuzzy number represented with three points as follows: $A=\left(a_{1}, a_{2}, a_{3}\right)$. This representation is interpreted as membership functions. 


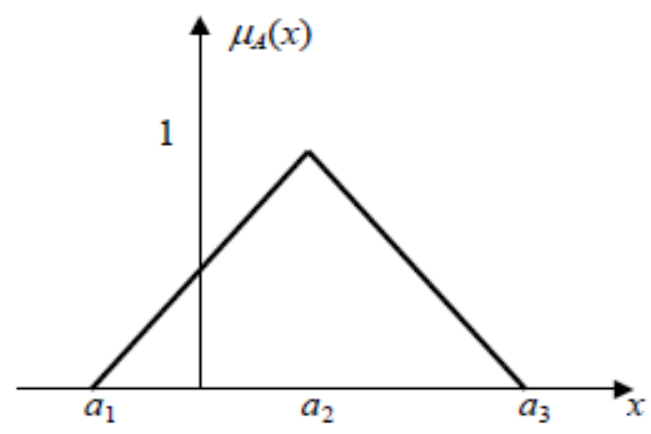

$$
\mu_{(.)}(x)= \begin{cases}0, & x<a_{1} \\ \frac{x-a_{1}}{a_{2}-a_{1}}, & a_{1} \leq x \leq a_{2} \\ \frac{a_{3}-x}{a_{3}-a_{2}}, & a_{2} \leq x \leq a_{3} \\ 0, & x>a_{3}\end{cases}
$$

From

$$
\frac{a_{1}^{(\alpha)}-a_{1}}{a_{2}-a_{1}}=\alpha, \quad \frac{a_{3}-a_{3}^{(\alpha)}}{a_{3}-a_{2}}=\alpha
$$

we get

$$
\begin{aligned}
& a_{1}{ }^{(\alpha)}=\left(a_{2}-a_{1}\right) \alpha+a_{1} \\
& a_{3}{ }^{(\alpha)}=-\left(a_{3}-a_{2}\right) \alpha+a_{3}
\end{aligned}
$$

The triangular fuzzy logic enables considering 3 variables involved in the design. 
Table 2 Rules used in fuzzy logic system

\begin{tabular}{|c|c|c|c|c|}
\hline & \multicolumn{3}{|c|}{ Input } & \multirow{2}{*}{\begin{tabular}{|c|} 
Output \\
Time of completion
\end{tabular}} \\
\hline Rule No & Angle Of Inclination & No Of Members & Degree Of Combination & \\
\hline 1 & $30^{\circ}$ & Minimum & Easy & Very short \\
\hline 2 & $30^{\circ}$ & Minimum & Medium & Short \\
\hline 3 & $30^{\circ}$ & Minimum & Difficult & Medium \\
\hline 4 & $30^{\circ}$ & Optimum & Easy & Short \\
\hline 5 & $30^{\circ}$ & Optimum & Medium & Medium \\
\hline 6 & $30^{\circ}$ & Optimum & Difficult & Long \\
\hline 7 & $30^{\circ}$ & Less & Easy & Medium \\
\hline 8 & $30^{\circ}$ & Less & Medium & Long \\
\hline 9 & $30^{\circ}$ & Less & Difficult & Very long \\
\hline 10 & $45^{0}$ & Minimum & Easy & Short \\
\hline 11 & $45^{0}$ & Minimum & Medium & Medium \\
\hline 12 & $45^{0}$ & Minimum & Difficult & Long \\
\hline 13 & $45^{0}$ & Optimum & Easy & Medium \\
\hline 14 & $45^{0}$ & Optimum & Medium & Long \\
\hline 15 & $45^{0}$ & Optimum & Difficult & Long \\
\hline 16 & $45^{0}$ & Less & Easy & Medium \\
\hline 17 & $45^{0}$ & Less & Medium & Long \\
\hline 18 & $45^{\circ}$ & Less & Difficult & Very long \\
\hline 19 & $60^{\circ}$ & Minimum & Easy & Short \\
\hline 20 & $60^{\circ}$ & Minimum & Medium & Medium \\
\hline 21 & $60^{\circ}$ & Minimum & Difficult & Long \\
\hline 22 & $60^{\circ}$ & Optimum & Easy & Medium \\
\hline 23 & $60^{\circ}$ & Optimum & Medium & Long \\
\hline 24 & $60^{\circ}$ & Optimum & Difficult & Very long \\
\hline 25 & $60^{\circ}$ & Less & Easy & Medium \\
\hline 26 & $60^{\circ}$ & Less & Medium & Very long \\
\hline 27 & $60^{\circ}$ & Less & Difficult & Very long \\
\hline
\end{tabular}

\section{CONCLUSION}

With the use of the tool kit and fuzzy logic, game explains the importance of effective communication / information flow for effective team work / group.

The tool kit / game can be used as a pedagogy in Human Resource Department or In supply chain department for importance of Information flow and conduction of experiments with scenarios.

\section{REFERENCES}

[1] Eva Imania Eliasa, Increasing Values of Teamwork and Responsibility of the Students through Games: Integrating Education Character in Lectures, Procedia - Social and Behavioral Sciences, Volume 123, 2014, Pages 196-203, https:// doi.org/10.1016/j.sbspro.2014.01.1415

[2] Tarricone, P. \& Luca, J. (2002) "Successful teamwork: A case study, in Quality Conversations", Proceedings of the 25th HERDSA Annual Conference, Perth, Western Australia, 7-10 July 2002: pp 640 
[3] Margaret T. Crichton, "Improving team effectiveness using tactical decision games”, Safety Science, Volume 47, Issue 3, 2009, Pages 330-336, https:// doi.org/10.1016/j.ssci.2008.07.036

[4] Edmondson, A.C. and Nembhard, I.M. (2009), Product Development and Learning in Project Teams: The Challenges Are the Benefits. Journal of Product Innovation Management, 26: 123-138.

https://doi.org/10.1111/j.1540-5885.2009.00341.x

[5] Stout, R. J., Cannon-Bowers, J. A., Salas, E., \& Milanovich, D. M. (1999). Planning, Shared Mental Models, and Coordinated Performance: An Empirical Link Is Established. Human Factors, 41(1), 61-71. https://doi.org/10.1518/001872099779577273

[6] Salas, E., Rozell, D., Mullen, B., \& Driskell, J. E. (1999). The Effect of Team Building on Performance: An Integration. Small Group Research, 30(3), 309329. https://doi.org/10.1177/104649649903000303

[7] ESalas, E., Cooke, N. J., \& Rosen, M. A. (2008). On Teams, Teamwork, and Team Performance: Discoveries and Developments. Human Factors, 50(3), 540-547. https://doi.org/10.1518/001872008X288457

[8] G M Parker, Team Players and Teamwork: The New Competitive Business Strategy (San Francisco: Jossey-Bass, 1990), Table 2, p 33. Copyright 1990 by Jossey-Bass Inc., Publishers. Reprinted by permission of John Wiley \& Sons, Inc. (table) 